\title{
Análise do processo de Reelaboração Discursiva na incorporação de um texto de Divulgação Científica no livro de Ciências
}

Pedro Henrique Ribeiro de Souza

Marcelo Borges Rocha

\begin{abstract}
Resumo
Neste artigo, investiga-se como se dá o processo de reelaboração discursiva de um texto de divulgação científica quando inserido em um livro didático de Ciências. A divulgação científica, importante fonte de conhecimento, caracteriza-se por um discurso informativo que, em certos casos, necessita sofrer adaptações para o uso em atividades pedagógicas. Desta forma investigou-se que mudanças ocorreram na linguagem, vocabulário, formas de argumentação, recursos visuais e natureza da ciência nos dois textos. Nossos resultados apontam para uma redução significativa do texto de divulgação ao ser inserido no livro didático, além de haver alteração para uma visão neutra e negativa da natureza da ciência. Com isso, reforça-se o papel do professor enquanto leitor crítico destes textos e mediador das atividades em que esses materiais são inseridos na sala de aula.

Palavras-chave: reelaboração discursiva, divulgação científica, Ensino de Ciências.

\section{Abstract \\ Analysis of the process of Discursive Reelaboration in the incorporation of a Popular Science text into a Science textbook}

This paper investigates the process of discursive reelaboration in a popular science text inserted into a science textbook. Popular Science is an important source of knowledge and is characterized by an informative speech which, in certain cases, it needs adaptations for its use in educational activities. Thus we investigated whether changes in language, vocabulary, forms of argument, visuals and nature of science in the two texts. Our results point to a significant reduction of the text to be inserted in the textbook and a change to a neutral and negative view of the nature of science. So it reinforces the role of the teacher as a critical reader of these texts and mediator of activities in which these materials are inserted in the classroom.
\end{abstract}

Keywords: discursive reelaboration, popular science, science teaching. 


\section{Introdução}

O ensino de ciências vem recebendo uma atenção especial em diversas partes do mundo, sobretudo devido ao enorme avanço científico e tecnológico, que causou um profundo impacto social, alterando o cotidiano da maioria das pessoas. Contudo, a maior parte da população ainda parece desconhecer a natureza da atividade científica, situação que é reforçada pela forma equivocada como a Ciência é abordada no contexto escolar (GIL-PERÉZ et al., 2001). Diante disto, deve-se buscar um ensino que permita aos alunos conceberem a natureza da ciência como uma atividade humana dinâmica, contextualizada e passível de erros, contribuindo para a formação de cidadãos críticos e capazes de tomar decisões em discussões científicas (PRAIA et al., 2007).

Os Parâmetros Curriculares Nacionais recomendam a incorporação de uma variedade de textos informativos como fontes alternativas de conhecimento, além do livro didático, pois cada um destes materiais possui estrutura e finalidade próprias (BRASIL, 2000). Nesta variedade, enquadram-se enciclopédias, livros paradidáticos, artigos de jornais e revistas, folhetos de campanhas de saúde, museus, textos da mídia informatizada, etc. Assim, estes textos podem contribuir para o ensino de ciências, no sentido de apresentar aos alunos uma diversidade de informações, além de possibilitar o desenvolvimento de habilidades de leitura, o domínio de conceitos, formas de argumentação e elementos da terminologia científica (MARTINS et al., 2001).

Portanto, neste contexto, artigos de divulgação científica (DC) enquadram-se como fontes alternativas de conhecimento científico para os alunos. Porém, cabe nos questionarmos: afinal, o que é DC?

De acordo com Loureiro (2003), a transmissão de conhecimento de qualquer área das ciências denomina-se difusão científica. Esta, de acordo com o público-alvo e a linguagem empregada, subdivide-se em disseminação científica, destinada para os especialistas, e divulgação científica, "voltada à circulação de informação em ciência e tecnologia para o público em geral" (LOUREIRO, 2003, p. 90).

Bueno (2010) ratifica esta diferença entre a comunicação científica e a DC no que diz respeito ao público. Enquanto na primeira os leitores estão familiarizados com os conceitos científicos, na segunda "ele (...) não tem, obrigatoriamente, formação técnico-científica que lhe permita, sem maior esforço, decodificar um jargão técnico ou compreender conceitos que respaldam o processo singular de circulação de informações especializadas" (BUENO, 2010, p. 2).

Orlandi (2001) caracteriza o discurso da DC como um discurso a parte, sendo formado pela união dos discursos científico, jornalístico e cotidiano. A autora aponta para a ocorrência de uma "metaforização" dos discursos científico e jornalístico na relação com o cotidiano, necessária para reduzir o uso excessivo de terminologias, o que torna o discurso da DC eficaz. 
Para Alferes e Agustini (2008), na DC ocorre uma vulgarização dos saberes científicos ao serem transpostos para um público não restrito. Tal processo pode afetar e transformar a concepção de ciência presente no senso comum, vista como forma de conhecimento acumulativo, sistematizável e atemporal. O propósito de transmitir uma visão de ciência neutra e utilitária, relacionada com o bem-estar da sociedade, é de caráter político, pois são privilegiados os resultados científicos referentes à tecnologia e à saúde, áreas de maior destaque na sociedade capitalista.

Neste trabalho, investigamos um caso de reelaboração discursiva de um artigo, originalmente publicado na Revista Terra da Gente ao ser inserido em um livro didático de Ciências de 6o ano do Ensino Fundamental. Inicialmente discutimos as bases teóricas de investigações acerca do uso destes textos no ensino de ciências e a natureza das reelaborações do discurso no contexto da educação científica. Em seguida, é apresentada uma breve descrição do material analisado e discutimos aspectos relacionados ao uso da linguagem e os recursos visuais em cada um dos textos e suas implicações em termos da visão de natureza da ciência. Ressaltamos em nossas análises alguns aspectos das reelaborações textuais resultantes da adaptação do texto original para o livro didático.

\section{Uso de textos de DC no Ensino de Ciências}

De acordo com Bueno (2010, p. 5), a função primordial da DC é "democratizar o acesso ao conhecimento científico e estabelecer condições para a chamada alfabetização científica." Desta forma, contribui para incluir os cidadãos em debates sobre temas específicos da ciência que podem impactar suas vidas e trabalho, como transgênicos, células tronco, mudanças climáticas, energias renováveis, dentre outros. Isto seria possível porque o divulgador está encarregado de "traduzir" os saberes científicos para o público leigo, articulando-se com outros discursos, como o pedagógico, o político e o religioso, a fim de tornar acessíveis tais conhecimentos (ALFERES e AGUSTINI, 2008).

O uso de textos de DC no ensino de ciências constitui-se numa prática marcante e gera discussões em diversos trabalhos (e.g. SILVA, 2006; PUIATI et al., 2007; KEMPER, 2008; FERREIRA e QUEIROZ, 2012). Em comum, estabelecem a importância dos textos como

"motivadores ou estruturadores da aula, organizadores de explicações, desencadeadores de debate e contextos para a aquisição de novas práticas de leitura, estabelecendo relações com o cotidiano dos alunos, ampliando seu universo discursivo e permitindo ressaltar aspectos da natureza da prática cientifica" (MARTINS et al., 2004, p. 95). 
Rocha (2010), em pesquisa realizada com professores de ciências do Ensino Fundamental, constatou que a DC possibilita a contextualização do conteúdo curricular e ainda proporciona aos alunos o acesso a informações que contribuem para a formação de cidadãos conscientes de seu papel na sociedade. $\mathrm{O}$ autor destaca, ainda, que o trabalho com tais textos possibilita

"(I) a reflexão, a interação e a interpretação dos fatos, facilitando o processo de reelaboração das informações pelos alunos, o que é fundamental para construção do conhecimento; (II) a ampliação da visão de mundo do aluno, na medida em que permite a discussão e a troca de opiniões a respeito dos fatos apresentados; (III) a ampliação do universo lexical e da competência linguística do aluno; (IV) a vinculação dos conteúdos curriculares à realidade, fazendo com que o aluno perceba o sentido e a aplicabilidade do que aprende na escola e (V) o desenvolvimento do hábito de leitura, seja por prazer ou por necessidade de buscar informações" (ROCHA, 2010, p. 32).

Para Gonçalves et al. (2011), o uso pedagógico de recursos midiáticos na sala de aula requer preparo do professor, face aos múltiplos significados dos conteúdos, assim como aos eventuais erros de informação. As autoras também destacam que, quando se fala em DC, devem ser considerados dois problemas: o do vínculo entre ciência e tecnologia, no qual a ciência não se restringe a um conhecimento puramente acadêmico, mas a serviço da sociedade, sustentada pelo mercado de consumo; e o grau de legitimidade atribuída a DC, bem como a acessibilidade ao público consumidor. Porém, isto não significaria torná-la irrelevante, uma vez que é importante porta de acesso para novos conhecimentos, além de ser elemento motivador para o ensino e complemento para o aprendizado em sala de aula.

De forma geral, as publicações de DC não apresentam o objetivo claro de tornar os leitores mais competentes em uma área do saber (GRILLO, et al., 2004). Embora seu conteúdo informativo contribua para a aquisição de conhecimento em determinada área, provocando rupturas no saber cotidiano, os textos de DC não possuem os mesmos objetivos pedagógicos de um livro didático (ROCHA, 2010). A apropriação destes textos para efeitos de ensino não pode ser automática, sendo necessário: estabelecer conexões entre o que abordam e os conteúdos curriculares; entender o funcionamento destes textos em cada contexto; e de que maneira estes textos são selecionados e adaptados para o uso em sala de aula, processo que envolve atividades de reelaboração discursiva dos mesmos (MARTINS et al., 2001).

É comum observar a inserção de textos de DC em livros didáticos de Ciências. Martins e Damasceno (2002) analisaram 6 coleções didáticas e constataram a presença de 83 textos escritos ou imagéticos de DC, sendo a maioria (84\%) provenientes de jornais e revistas. Além disso, boa parte dos textos (65\%) sofreu algum tipo de adaptação para a sua inclusão no livro didático. Nascimento (2005) também identificou a presença de textos de DC adaptados nos livros, o que 
corrobora seus diferentes discursos e funções, além da forma como o leitor irá interagir, seja no ambiente informal ou no escolar.

\section{0 processo de Reelaboração Discursiva}

Um processo de reelaboração discursiva consiste em uma forma de movimento textual no qual há modificação por conta do tipo de contexto em que a adaptação é necessária (MARTINS et al., 2001). Neste caso, chama-se a atenção para a importância de um processo de reelaboração discursiva que emerge da necessidade de recontextualização do tema abordado pelo texto de DC em relação ao conteúdo trabalhado em sala de aula. Na literatura, é possível encontrar análises de casos de reelaboração discursiva na adaptação de textos de DC para textos de caráter didático, seja realizada por autores de livros didáticos para incorporação destes textos nas coleções, ou por professores em atividades pedagógicas.

Martins et al. (2001) analisaram um caso de reelaboração discursiva de um texto de DC, que abordava a dinâmica do fogo no Cerrado, para um texto presente em um livro didático do Ensino Médio, vinculado ao tema Ecologia. Os autores constataram uma redução significativa de informação nesta adaptação, inclusive com modificação da natureza da ciência, de uma construção dinâmica no texto de DC para neutra e objetiva no texto didático. Além disso, houve perda na função das imagens, que eram informativas no texto de DC para meramente ilustrativas no texto didático.

Martins et al. (2004) utilizaram um texto de DC em sala de aula, para um curso noturno, no qual a professora adaptou o texto antes de trabalhá-lo com seus alunos. Entre as reelaborações discursivas realizadas pela professora destacam-se adaptações do texto original tornando-o menor para o uso em aula, introdução de atividades de leitura, de forma livre e dirigida, e utilização conjunta com textos didáticos. Após a análise das aulas, observou-se que o texto de divulgação científica motivou a participação dos alunos, forneceu explicações para o conteúdo curricular e, ainda, estimulou a prática de leitura.

Nascimento (2005) analisou as operações de reelaboração discursiva sofridas por um texto de DC sobre clonagem ao ser inserido em um LD de ciências. O estudo revelou que o texto de DC, cuja principal função é promover a atualização de conteúdos, não estabelece conexões com as demais partes do livro, mantendo, ainda, as principais características do discurso da divulgação. Em trabalho posterior da mesma autora (NASCIMENTO, 2008), discute-se acerca das atividades de reelaboração discursiva em textos de divulgação científica adaptados por licenciandos para suas aulas de regência, destacando a relevância do licenciando como mediador do texto de divulgação científica na sala de aula.

Rocha (2010), em seu estudo, entrevistou professores de ciências, investigando a forma como selecionam, adaptam e trabalham textos de divulgação científica em sala de aula. A 
despeito das vantagens de suas utilizações pelos professores, o autor destaca a necessidade de "aprofundar as discussões acerca da incorporação didática destes materiais, de como eles podem complementar os livros didáticos, e da natureza das reelaborações discursivas envolvidas na articulação com temas do currículo de ciências" (ROCHA, 2010, p. 25).

\section{Desenho Metodológico}

\subsection{Textos analisados}

Este trabalho faz parte de uma pesquisa mais ampla, que busca identificar textos de divulgação presentes em livros didáticos, analisando de que forma são reelaborados nesta incorporação. Desta forma, os textos analisados neste trabalho foram identificados a partir de uma pesquisa em coleções didáticas de Ciências do Ensino Fundamental recomendadas pelo Programa Nacional do Livro Didático (PNLD), amplamente adotadas pelas escolas públicas.

O texto de divulgação (TDC) adaptado para o livro de ciências intitula-se "Onças cativas", do jornalista Jaime Geisisky. Publicado originalmente na Revista Terra da Gente, especializada em artigos sobre a biodiversidade brasileira, em abril de 2005, possui no total 7 (sete) páginas. Como a versão original, publicada na revista, não foi encontrada, a análise foi realizada a partir da versão on line, apresentando 2467 palavras, 33 parágrafos e 5 fotos, quatro enfocando as onças pintadas e apenas uma destacando a onça parda. No site da revista, encontra-se a informação de que a matéria recebeu Menção Honrosa no Prêmio de Reportagem de Biodiversidade da Mata Atlântica, em 2006 (TERRA DA GENTE, 2012).

O TDC inicia expondo a problemática do risco de extinção das duas espécies de onças no Brasil: a pintada (Panthera onca) e a parda (Puma concolor), expondo, em linhas gerais, as causas deste risco - em geral, perda de habitats e encontros com humanos - e a problemática de zoológicos e criadouros, nos quais as onças entram e não saem, sem condições de retornar ao ambiente natural. $\mathrm{O}$ texto segue descrevendo sobre o custo de seu cativeiro, problemas ligados à sua reintrodução ao ambiente silvestre e o desenvolvimento de pesquisas em genética para auxiliar esse retorno. Em outra seção do artigo, comenta-se sobre a questão dos encontros entre onças e seres humanos, sendo que estes, por medo ou represália, lançam mão de caçadas e armadilhas para matá-las. Por fim, o texto faz uma breve descrição etiológica das duas espécies de onça do país, contendo informações sobre habitat, distribuição geográfica, hábitos alimentares, comportamentos reprodutivos e cuidados parentais.

O texto didático (TD) intitula-se "Riscos nas cadeias alimentares" e está presente na coleção "Ciências - o Meio Ambiente" 6 ano, de Carlos Barros e Wilson Paulino, 4ạ edição, publicada em 2011. O texto representa a seção "Desafios do presente", na página 35 do Capítulo 3 , intitulado "A transferência de energia e de matéria num ecossistema". Este capítulo trata de 
questões ligadas ao fluxo de energia e aos ciclos de matéria em um ecossistema, abordando questões relativas ao papel dos organismos nestes processos e nas relações alimentares, como cadeias e teias. Também é integrante da Unidade I, intitulada "Os seres vivos e o ambiente", que aborda conteúdos do tema Ecologia, pertinente ao programa do sexto ano do Ensino Fundamental, contendo, em outros capítulos, conceitos como biosfera, relações ecológicas, biomas e impactos ambientais. $O$ texto possui apenas uma página, contendo 264 palavras em 4 parágrafos e apenas uma foto, diferente das fotos da versão on line do TDC.

O TD expõe as principais causas da redução de habitats das onças, informa os seus hábitos alimentares e explora os motivos e consequências de um encontro acidental entre uma onça e um ser humano, considerado um dos maiores fatores responsáveis pelo risco de extinção destas espécies. Ao fim, comenta-se sobre a falta de investimentos para conservação das onças e necessidade de conscientização, por parte da população, para a preservação destes animais.

\subsection{Análise dos artigos}

A análise foi realizada discutindo aspectos relacionados à linguagem, aos recursos visuais e à natureza da ciência em ambos os textos. Para a análise das reelaborações discursivas sofridas pelo texto de divulgação científica ao ser adaptado para o livro didático, foram utilizadas as categorias segundo Gomes (1995), que são: eliminação, reordenação, substituição e acréscimo.

\section{Resultados da análise}

\subsection{A linguagem dos textos}

A linguagem do TDC apresenta uma maior densidade lexical, ou seja, concentra muitos termos léxicos em uma mesma sentença e utiliza-se de recursos narrativos e exemplificações. $O$ TD, por sua vez, apresenta menor densidade lexical e assume um caráter mais descritivo, utilizando poucos termos técnicos. 0 trecho ilustrado no quadro 1 corresponde ao 18으 parágrafo do TDC e ao 1 parágrafo do TD. Através destes trechos, é possível observar as modificações sofridas durante a produção textual para a inserção no livro didático. No TD, o texto assume um caráter mais explicativo e objetivo. Vale destacar que isso se deve ao fato de que tanto o texto de divulgação quanto o didático estarem estruturados a partir das necessidades, interesses e competências do público leitor. 
Quadro 1 - Comparação entre a linguagem de um trecho do texto de divulgação e outro do texto didático.

Texto de Divulgação Científica

\begin{tabular}{|c|c|}
\hline $\begin{array}{l}\text { dovias e hidrelétricas, a supressão das } \\
\text { orestas nativas deixa as onças } \\
\text { emasiadamente vulneráveis. Como } \\
\text { edadores, animais de topo de cadeia }\end{array}$ & $\begin{array}{l}\text { mais o } \\
\text { no }\end{array}$ \\
\hline
\end{tabular}

Texto Didático

Outro aspecto importante no que diz respeito à linguagem é que os dois textos utilizam metáforas, auxiliando o entendimento de conceitos e de ideias abstratas. 0 quadro 2 apresenta alguns exemplos que ilustram essa situação. O TD se vale do uso de aspas nas palavras consideradas como metáforas, além de escrevê-las no singular e acrescendo complementos que não estavam presentes no TDC. A colocação destas aspas é passível de discussão, pois os termos em questão são utilizados de forma comum em textos científicos, sejam eles acadêmicos ou didáticos, mesmo apresentando outras conotações envolvidas com o cotidiano. Foi possível observar, ainda, acréscimos durante o processo de reelaboração destes trechos, o que será discutido mais adiante.

Quadro 2 - Comparação entre as metáforas do texto de divulgação e do texto didático.

Texto de Divulgação Científica

Texto Didático

\begin{tabular}{|c|c|}
\hline $\begin{array}{l}\text { “... podem se tornar atraentes.” - 23ㅇ } \\
\text { parágrafo }\end{array}$ & $\begin{array}{l}\text { “... podem representar uma 'atraente' opção } \\
\text { alimentar." - 3o parágrafo }\end{array}$ \\
\hline com os conflitos." - & $\begin{array}{l}\text { “... acabar com o 'conflito' de interesses." - } \\
\text { 3ㅇ parágrafo }\end{array}$ \\
\hline
\end{tabular}

Durante a análise, observou-se muitas substituições de termos, como 'supressão' por 'eliminação', 'agropecuária' por 'cultivo de plantas' e 'criação de gado' e 'demasiadamente vulneráveis' por 'aumenta cada vez mais o risco de extinção'. Além disso, no parágrafo introdutório do TD, o texto possui algumas alterações estruturais para torná-lo menos argumentativo e mais descritivo, como a inclusão de 'campos' junto às 'florestas' como o território suprimido e estendendo a problemática a 'diversos animais no Brasil'. Tais mudanças 
tornam a leitura do TD mais didática em relação ao TDC, pois tornam o vocabulário menos complexo para alunos do 6ㅇ ano do Ensino Fundamental, na faixa dos 11 anos de idade.

\subsection{Os recursos visuais}

As imagens da versão on line do TDC são puramente ilustrativas, enfocando quatro onças pintadas e uma parda em cativeiro, motivando o interesse do leitor e tornando o texto esteticamente mais agradável á leitura (Figura 1).

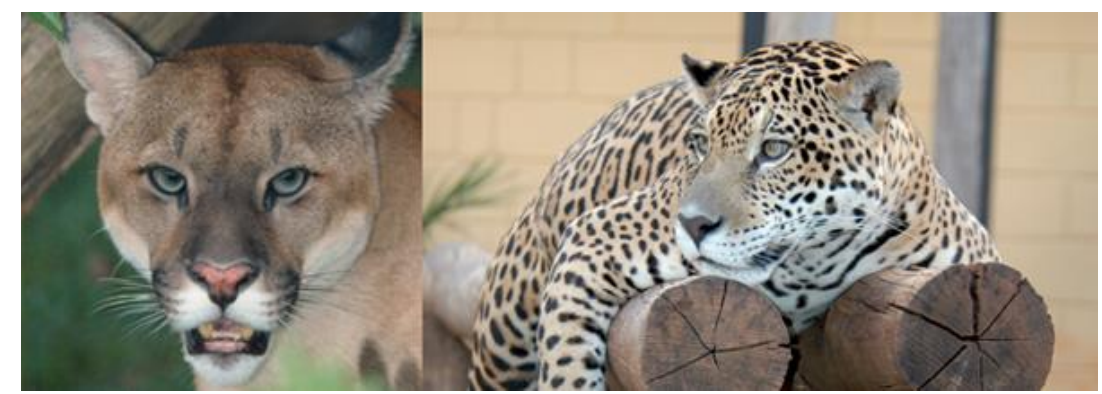

Figura 1 - Fotografias de onça parda (esquerda) e onça pintada (direita)

que compõem o TDC.

(Fonte: Geisisky, 2005)

A imagem do TD, além de ter função ilustrativa, possui também uma função informativa, pois apresenta uma legenda cuja explicação não está presente no texto, relacionada com distribuição geográfica da onça parda (Figura 2). Além disso, a foto da onça parda que compõe o TD, que não é a mesma presente no TDC, é de uma onça aparentemente em ambiente natural, o que se opõe às imagens do TDC, provavelmente porque o TD não menciona a situação de onças em cativeiro.

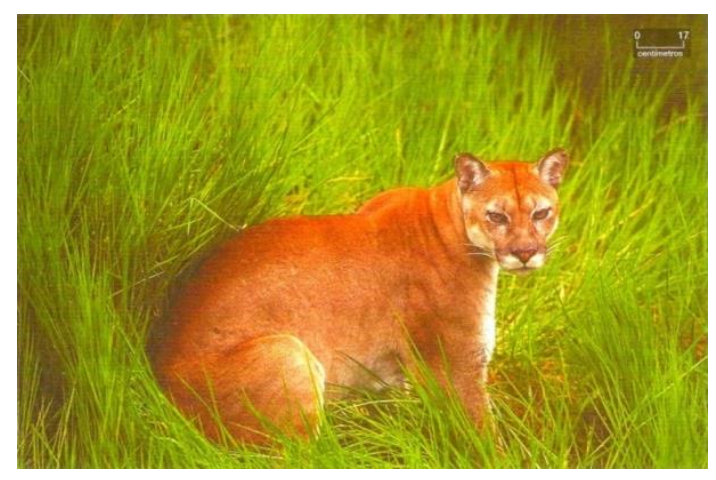

Figura 2 - Fotografia que compõe o TD.

(Fonte: Barros e Paulino, 2011) 


\subsection{As reelaborações discursivas}

O sentido original do texto de divulgação é parcialmente preservado no TD, variando apenas na intenção de cada texto. Enquanto o TDC busca explorar as dificuldades e as estratégias de conservação, como métodos genéticos para auxiliar na reintrodução de espécimes criados em cativeiro ou mudanças na forma de se lidar com o contato acidental com as onças, o TD apenas relata as causas do risco de extinção. O TDC também apresenta relatos com pesquisadores a respeito do assunto e narra uma pequena história de um fazendeiro que, após perder ovelhas, é orientado por autoridades ambientais públicas a não caçar as onças responsáveis. Tais passagens não estão presentes no TD, que apenas generaliza a situação das espécies de onça no Brasil, sem relatar casos particulares.

O texto reduziu de forma expressiva, passando de sete páginas no TDC a apenas uma página. O número de palavras diminui de cerca de 2600 para 264 e de 33 parágrafos para apenas quatro. Com essa redução, o TD não aborda, em nenhum momento, questões relativas à criação em cativeiro de onças e pesquisas relacionadas ao mapeamento genômico dos indivíduos a fim de contribuir para sua reintrodução ao ambiente natural. Dois casos de eliminação de pequenas expressões foram identificados e estão presentes no quadro seguinte.

Quadro 3 - Metáforas do texto de divulgação e do texto didático.

Texto de Divulgação Científica

\section{Texto Didático}

\footnotetext{
"Ao sair em busca de alimento..." - 19 "Na busca do alimento,..." - 3o parágrafo parágrafo

"Não importa, ao menor sinal dos felinos, logo "Então, entram em ação os tiros, as surgem armadilhas, caçadas, tiros." - 23ㅇ armadilhas e as caçadas." - 3o parágrafo parágrafo
}

O recurso da reordenação foi muito utilizado, para facilitar a leitura e a fluência do texto, considerando sua expressiva redução. De forma global, pode-se constatar uma grande reordenação nesta nova estruturação do texto, pois os três primeiros parágrafos do TD correspondem aos 18ำ, 19 e 23ำ parágrafos do TDC e o último parágrafo do TD, ao 16ㅇ parágrafo do TDC. Elementos das descrições das duas espécies de onça, que estão nos 26으, 31으 e 32은 parágrafos aparecem misturados com outras partes do texto, como no segundo parágrafo, onde são listadas as presas das duas espécies de onça, sem diferenciá-las, ou na legenda da foto, na qual estão algumas características da onça parda ou suçuarana. $O$ quadro 4 resume os casos de reordenação identificados na adaptação do TDC para o TD. 
Quadro 4 - Comparação entre os casos de reordenação do texto de divulgação e do texto didático.

Texto de Divulgação Científica

\footnotetext{
"Apesar de não pertencer ao gênero Panthera [sic] e nem à espécie $P$. onca [sic], é tratada como tal. Também conhecida como suçuarana, leão-baio, puma e leão-da-montanha, ocorre do sudoeste do Canadá até o Estreito de Magalhães, no extremo sul da Argentina/Chile. É, portanto, o felino de maior área de distribuição geográfica do continente americano." - 310 parágrafo

“Caçam preferencialmente roedores de médio a grande porte, como a paca (Agouti paca) [sic] e primatas." - 260 parágrafo

“...alimenta-se de animais silvestres de portes variados, desde aves até veados e queixadas (Tayassu pecari) [sic]." - 32o parágrafo “... para a conservação e pesquisa com animais silvestres..." - 160 parágrafo
}

\section{Texto Didático}

"Onça-parda, também conhecida como suçuarana, leão-baio, puma e leão-damontanha, entre outros nomes populares. Esse animal pode ser encontrado em várias regiões do continente americano." - legenda da foto

$$
\begin{aligned}
& \text { “... e da quantidade de presas como ratos, } \\
& \text { capivaras, cutias, pacas, macacos, veados e } \\
& \text { porcos-do-mato." - 20 parágrafo }
\end{aligned}
$$

Muitas substituições também foram encontradas, sobretudo por trocas de palavras sinônimas ou de expressões por outras de sentidos similares. O primeiro parágrafo do TD é um caso a parte de substituição, pois, como relatado acima, ocorre uma ampla alteração na estrutura do período, também envolvendo acréscimo de elementos para torná-lo mais explicativo. 0 quadro 5 apresenta este e outros casos de substituição identificados. 
Quadro 5 - Comparação entre os casos de substituição do texto de divulgação e do texto didático.

Texto de Divulgação Científica

\begin{abstract}
"Seja para o avanço da agropecuária, devido ao crescimento urbano ou grandes obras, como rodovias e hidrelétricas, a supressão das florestas nativas deixa as onças demasiadamente vulneráveis." - 18o parágrafo

nction
"Um indivíduo macho adulto chega a ocupar "Uma onça adulta explora uma área entre 20 entre 22 e $150 \mathrm{~km}^{2}$ dependendo da região e da e $150 \mathrm{~km}^{2}$, dependendo da região e da disponibilidade de alimentos." - 19 parágrafo quantidade de presas." - 2o parágrafo “... da importância dele se adaptar à “... a importância de ajustar-se à convivência convivência com os predadores." - 16 com os predadores..." - 40 parágrafo parágrafo

O acréscimo foi outro recurso que apareceu durante a reelaboração, principalmente com o objetivo de explicar termos cujo significado não faz parte do cotidiano dos alunos ou, ainda, para tornar a leitura mais fluente. O primeiro caso de acréscimo, relacionado junto aos demais encontrados nesta adaptação no quadro 6, altera o significado do período na medida em que adiciona o verbo 'poder' ao verbo 'topam', formando a locução verbal 'podem topar', retirando um caráter de afirmação para atribuir um caráter de possibilidade.
\end{abstract}

\title{
Quadro 6 - Comparação entre os casos de acréscimo do texto de divulgação e do texto didático.
}

Texto de Divulgação Científica

Texto Didático

\begin{tabular}{|c|c|}
\hline "... elas topam..." - 19o parágrafo & “... elas podem topar..." - 3o parágrafo \\
\hline “... presas silvestres..." - 23으 parágrafo & $\begin{array}{l}\text { “... presas silvestres (que vivem em matas } \\
\text { naturais, como florestas)." - 3o parágrafo }\end{array}$ \\
\hline “... ainda são as alternativas mais usadas..." - & "... essas ações são alternativas ainda usadas" \\
\hline 23ㅇp parágrafo & - 3o parágrafo \\
\hline $\begin{array}{l}\text { “... convivência com os predadores." - 16을 } \\
\text { parágrafo }\end{array}$ & $\begin{array}{l}\text { "... convivência com os predadores que vivem } \\
\text { em nossas matas." - } 4 \text { o parágrafo }\end{array}$ \\
\hline
\end{tabular}




\subsection{Natureza da ciência}

Em relação à natureza da ciência transmitida pelos textos, o TDC expõe, em geral, uma visão crítica da situação, com inclinação negativa para a questão do risco de extinção, perda de habitats, caçadas e criação em cativeiro. Porém, notam-se apontamentos otimistas no tocante à questão de estudos genômicos e de conscientização de fazendeiros, inclusive propondo soluções legais para afastar as onças de território humano. Relatos de pesquisadores estão presentes no TDC, bem como uma pequena passagem sobre um fazendeiro que mudou sua postura mesmo sendo prejudicado por uma onça, características de um texto jornalístico, apresentando uma ciência construída por pessoas, com suas limitações, e interferindo em aspectos sociais.

O TD também mostra uma visão crítica e inclinada negativamente para os mesmos fatores que colocam as onças em risco de extinção, porém mantém-se pessimista e atribui um peso maior para a conscientização da população no sentido de evitar o desaparecimento destes animais. Pela linguagem simplificada e ausência dos relatos, menção às pesquisas e pequenas narrativas, a visão de ciência construída pelo TD é neutra e objetiva, assim como observado nos resultados produzidos por Martins et al. (2001).

Assim, acredita-se que houve alteração na visão da natureza da ciência de um texto para o outro, o que é um aspecto negativo da reelaboração, pois inviabiliza ao aluno identificar que a ciência não está dissociada do contexto socioambiental, já que as soluções propostas são omitidas. Promove-se uma visão socialmente neutra da atividade científica, na qual "esquecem-se as complexas relações entre ciência, tecnologia, sociedade (CTS) e proporciona-se uma imagem deformada dos cientistas como seres "acima do bem e do mal", fechados em torres de marfim" (GIL-PÉREZ et. al, 2001, p. 133).

O quadro abaixo ilustra passagens dos textos onde esta diferença pode ser percebida.

Quadro 7 - Comparação da visão de Natureza da Ciência entre o texto de divulgação e o texto didático.

Texto de Divulgação Científica

\section{Texto Didático}

"Quanto menos presas disponíveis, mais as onças têm de caminhar. $\mathrm{Na}$ busca do alimento, elas podem topar com fronteiras estabelecidas pelo ser humano. $\mathrm{E}$ o encontro com o ser humano pode decidir o destino do animal. Se as presas silvestres (que vivem em matas naturais, como florestas) tornam-se muito raras, as novilhas, as ovelhas e as aves domésticas podem representar uma 'atraente' opção alimentar. Então, entram

R. B. E. C. T., vol 7, núm. 1, jan-abr.2014 ISSN - 1982-873X 
destino do animal. Afinal, as onças querem comida e se as presas silvestres se tornam muito raras, as novilhas, as ovelhas e as aves domésticas podem se tornar atraentes. Às vezes, a onça está por perto, deixa rastros, mas não é responsável pelo sumiço de alguns animais do rebanho. Não importa, ao menor sinal dos felinos, logo surgem armadilhas, caçadas, tiros. Embora ilegais, ainda são as alternativas mais usadas para acabar com os conflitos." - 23 parágrafo em ação os tiros, as armadilhas e as caçadas. Embora ilegais, essas ações são alternativas ainda usadas para acabar com o 'conflito' de interesses." - 3ำ parágrafo

\section{Considerações finais}

Segundo Grillo et al. (2004, p. 216), enquanto os livros didáticos representam formas de discursos didáticos, com fins pedagógicos, "as publicações de divulgação científica podem ser caracterizadas como representantes de discursos estritamente informativos e que não manifestariam nenhuma intenção de tornar o outro mais competente em uma área de saber." Portanto, o TDC não tem o real comprometimento de ensinar, de tornar o sujeito mais competente na área do saber que é contemplada em sua matéria, tarefa essa delegada ao TD. 0 TDC possui um caráter meramente informativo, que não revela, em momento algum, a intenção de tornar o leitor especialista no assunto, no caso, os riscos de extinção e estratégias de conservação das populações das duas espécies de onças. De forma similar, o TD se propõe a transmitir um conhecimento a ser assimilado pelos alunos, como forma de garantir sua formação nesta área do ensino, portanto apresenta linguagem com menor densidade lexical e acrescenta certas explicações de termos que se encontram no TDC. Deve-se ressaltar que, se por um lado isso torna a leitura mais acessível para os alunos, por outro nos faz refletir sobre os riscos destas operações transformarem recursos linguísticos que caracterizam a atividade científica.

Inegavelmente, há redução significativa na adaptação de um texto para o outro, pois houve diminuição considerável no número de palavras, tornando o texto compatível com apenas uma página do livro didático à qual estava destinado. O TD também não se propôs a abordar questões ligadas à conservação das espécies de onça, assim como a importância de pesquisas ligadas ao genoma destes animais, enfocadas pelo TDC. As fotos do TDC enfocam onças presas em cativeiro, enquanto a única foto do TD apresenta uma onça em seu ambiente natural. O enfoque do TD é mais ecológico, ligado à relação dos animais com seus habitats, relações alimentares e com o ser humano, ou seja, está mais articulado com o conteúdo curricular para o qual o livro se destina. Prova disto é que os parágrafos utilizados do TDC para a produção do TD apenas mencionavam os aspectos de interesse dos autores do livro didático para a adaptação. O motivo 
para tal adaptação é o fato que o TD está inserido em um capítulo que trata das relações alimentares entre os seres vivos, sendo o texto alocado na seção "Desafios do presente", que tem por finalidade trazer uma problemática relacionada ao assunto trabalhado no capítulo. Portanto, o conteúdo eliminado nesta adaptação não era pertinente à linha temática abordada neste momento do livro didático.

Quanto ao uso em sala de aula, o TDC revela ser um bom texto para se trabalhar no Ensino Médio, devido à maior densidade de termos científicos em relação ao TD, tendo discussões sobre pesquisa em genética de populações e sobre natureza da ciência. Já o TD é ideal para se trabalhar no Ensino Fundamental, devido à fluência da leitura e pelas discussões ambientais envolvidas, cabendo ao professor desenvolver uma leitura crítica com os alunos. Se o professor tiver contato com o texto original do qual houve a adaptação, pode salientar o papel de pesquisas complementares para a conservação das espécies de onças e trabalhar estas informações com os alunos.

Os resultados deste trabalho coincidem com os de Nascimento (2005), no que diz respeito à intencionalidade da adaptação do TDC no livro didático. De acordo com a autora, não muda apenas a composição linguística do texto, mas também seu público alvo e objetivos. O papel assumido por este tipo de texto, enquanto apenas um elemento composicional a mais no livro didático, é inserir assuntos atuais. Como o livro normalmente possui formato e estrutura conservadores, tais artigos podem contribuir para dar conta de apropriar-se de conhecimentos recentes, aspecto problemático do ensino de ciências no âmbito formal. Esta prática torna-se mais relevante se compararmos a periodicidade da publicação dos livros didáticos, cujas edições mudam a cada três anos, em relação a de artigos trazendo novidades científicas, com publicações diárias.

Como sugerem outros trabalhos na área (MARTINS et al., 2001; NASCIMENTO, 2005; NASCIMENTO, 2008; ROCHA, 2010), existe a necessidade de maior produção de trabalhos com este enfoque, para se entender de que forma os textos são adaptados e que reelaborações discursivas estão envolvidas. Desta forma, identificam-se as alterações epistemológicas que o texto original pode sofrer, cabendo uma leitura crítica dos professores antes de trabalhar com estes materiais em sala de aula.

\section{Referências}

ALFERES, Sirlene; AGUSTINI, Carmen. A Escrita da Divulgação Científica. Horizonte Científico, v. 2, n.1, p. 1-23. 2008.

BARROS, Carlos; PAULINO, Wilson. Ciências - o meio ambiente: 6o ano. 4.ed. São Paulo: Ed. Ática, 2011. p. 35.

R. B. E. C. T., vol 7, núm. 1, jan-abr.2014 ISSN - 1982-873X 
BRASIL, Secretaria de Educação Fundamental. Parâmetros Curriculares Nacionais: Terceiro e quarto ciclos do ensino fundamental. Brasília: MEC/SEF, 2000.

BUENO, Wilson. Comunicação científica e divulgação científica: aproximações e rupturas conceituais. Informação \& Informação, Londrina, v. 15, n. esp, p. 1-12, 2010.

FERREIRA, Luciana; QUEIROZ, Salete. Textos de Divulgação Científica no Ensino de Ciências: uma revisão. Revista de Educação em Ciência e Tecnologia, v. 5, n. 1, p. 3-31, maio 2012.

GEISISKY, J. Onças cativas. Terra da Gente, ano 1, n. 12, p. 19-25, abr/2005. Disponível em <http://eptv.globo.com/terradagente/NOT,0,0,270309,Oncas+cativas.aspx> Acesso em: 02 set. 2012.

GOMES, Isaltina. Dos laboratórios aos jornais: Um estudo sobre o jornalismo científico. 1995. Dissertação (Mestrado em Linguística), Centro de Artes e Comunicação, UFPE, Recife/PE: abril de 1995.

GIL-PERÉZ, Daniel; FERNÁNDEZ, Isabel; CARRASCOSA, Jaime; CACHAPUZ, António; PRAIA, João. Para uma imagem não deformada do trabalho científico. Ciência \& Educação, Bauru, v. 7, n. 2, p. 125-153, dez. 2001.

GONÇALVES, Elizabeth; CALDAS, Graça; PECHULA, Márcia. Mídia e Educação: reflexões sobre o uso pedagógico de textos de divulgação científica. In: REUNIÃO BIENAL DA RED POP, 12., 2011. Campinas. Anais... Campinas/SP: Unicamp, 2011. 10 p.

GRILLO, Sheila; DOBRANSZKY, Enid; LAPLANE, Adriana. Mídia impressa e educação científica: uma análise das marcas do funcionamento discursivo em três publicações. Cadernos Cedes, Campinas, v. 24, n. 63, p. 215-236, maio/ago. 2004.

KEMPER, Alessandra. A evolução biológica e as revistas de divulgação científica: potencialidades e limitações para o uso em sala de aula. Dissertação (Mestrado em Educação), Faculdade de Educação, UnB, Brasília/DF: março de 2008.

LOUREIRO, José Mauro. Museu de ciência, divulgação científica e hegemonia. Ciência da Informação, Brasília, v. 32, n. 1, p. 88-95, jan./abr. 2003.

MARTINS, Isabel; CASSAB, Mariana; ROCHA, Marcelo. Análise do processo de reelaboração discursiva de um texto de divulgação científica para um texto didático. Revista Brasileira de Pesquisa em Educação em Ciências, São Paulo, v. 1, n. 3, p. 1-9, set./dez. 2001.

MARTINS, Isabel; DAMASCENO, Allan. Uma análise das incorporações de textos de divulgação científica em livros didáticos de ciências. In: ENCONTRO DE PESQUISA EM ENSINO DE FÍSICA, 8., 2002. Atas... São Paulo: SBF, 2002. 10 p. 
MARTINS, Isabel; NASCIMENTO, Tatiana; ABREU, Téo. Clonagem na sala de aula: um exemplo de uso didático de um texto de divulgação científica. Investigações em Ensino de Ciências, Porto Alegre, v. 9, n. 1, p. 95-111, mar. 2004.

NASCIMENTO, Tatiana. $\mathbf{O}$ texto de Genética no livro didático de Ciências: uma análise retórica. Dissertação (Mestrado em Educação em Ciências e Saúde), NUTES, UFRJ, Rio de Janeiro/RJ: dezembro de 2003.

NASCIMENTO, Tatiana. O discurso da divulgação científica no livro didático de ciências: características, adaptações e funções de um texto sobre clonagem. Revista Brasileira de Pesquisa em Educação em Ciências, São Paulo, v. 5, n. 2, p. 1-13, maio/ago. 2005.

NASCIMENTO, Tatiana. Leituras de divulgação científica na formação inicial de professores de ciências. Tese (Doutorado em Educação Científica e Tecnológica), Centro de Ciências da educação, UFSC, Florianópolis/SC: junho de 2008.

ORLANDI, Eni. Divulgação Científica e efeito leitor: uma política social urbana. In: . (Org.). Discurso e texto: Formulação e circulação dos sentidos. Campinas/SP: Pontes, 2001. p. 149-162. PRAIA, João; GIL-PÉREZ, Daniel; VILCHES, Amparo. O papel da Natureza da Ciência na Educação para a Cidadania. Ciência \& Educação, Bauru, v. 13, n. 2, p. 141-156, jun. 2007.

PUIATI, Lidiane; BOROWSKY, Halana; TERRAZZAN, Eduardo. O texto de divulgação científica como recurso para o ensino de ciências na educação básica: um levantamento das produções nos ENPEC. In: ENPEC, 6., 2007, Florianópolis. Anais... Florianópolis: ABRAPEC, 2007.

ROCHA, Marcelo. Textos de divulgação científica na sala de aula: a visão do professor de ciências. Revista Augustus, Rio de Janeiro, v. 14, n. 29, p. 24-34, fev. 2010.

SILVA, Henrique. O que é Divulgação Científica. Ciência \& Ensino, Campinas, vol. 1, n. 1, p. 53-59, dez. 2006.

TERRA DA GENTE. Disponível em <http://eptv.globo.com/terradagente> Acesso em: 02 set. 2012.

Pedro Henrique Ribeiro de Souza é mestre em Ciência, Tecnologia e Educação pela CEFET/RJ. È professor de Biologia do Estado do Rio de Janeiro e da FAETEC.

Email: pedrohrsouza@hotmail.com

Marcelo Borges Rocha é doutor em Ciências Biológicas pela Universidade Federal do Rio de Janeiro e professor do CEFET/RJ. Email: rochamarcelo36@yahoo.com.br 